\title{
Detection of CMY-type beta-lactamases in Escherichia coli isolates from paediatric patients in a tertiary care hospital in Mexico
}

\author{
Jocelin Merida-Vieyra ${ }^{1}$, Agustín De Colsa-Ranero ${ }^{1,2}$, Yair Calderón-Castañeda ${ }^{3}$ \\ and Alejandra Aquino-Andrade ${ }^{1^{*}}$ (B)
}

\begin{abstract}
Background: The aim of this study was to detect CMY-type beta-lactamases in E. coli isolates obtained from paediatric patients.

Methods: In total, 404 infection-causing E. coli isolates resistant to third and fourth generation cephalosporins (3GC, 4GC) were collected from paediatric patients over a 2 years period. The identification and susceptibility profiles were determined with an automated microbiology system. Typing of bla $a_{\mathrm{CMY}}$ and other beta-lactamase genes $\left(b / a_{\mathrm{TEM}}, b / a_{\mathrm{SHV}}\right.$, bla $a_{\mathrm{CTX}-\mathrm{M}}, b / a_{\mathrm{VIM}}, b / a_{\mathrm{IMP}}, b / a_{\mathrm{KPC}}, b / a_{\mathrm{NDM}}, b / a_{\mathrm{OXA}}$ and $\left.b / a_{\mathrm{GES}}\right)$ was realized by PCR and sequencing. Phenotypic detection of AmpC-type enzymes was performed using boronic acid $(20 \mathrm{mg} / \mathrm{mL})$ and cloxacillin $(20 \mathrm{mg} / \mathrm{mL})$ as inhibitors, and the production of extended-spectrum beta-lactamases was determined with the double-disk diffusion test with cefotaxime (CTX) and ceftazidime (CAZ) discs alone and in combination with clavulanic acid. The CarbaNP test and modified carbapenem inhibition method (mCIM) were used for isolates with decreased susceptibility to carbapenems. The clonal origin of the isolates was established by pulsed-field gel electrophoresis (PFGE), phylotyping method and multilocus sequence typing.
\end{abstract}

Results: CMY-type beta-lactamases were detected in 18 isolates (4.5\%). The allelic variants found were CMY-2 $(n=14)$ and CMY-42 $(n=4)$. Of the E. coli strains with CMY, the AmpC phenotypic production test was positive in 11 isolates with cloxacillin and in 15 with boronic acid. ESBL production was detected in 13 isolates. Coexistence with other beta-lactamases was observed such as CTX-M-15 ESBL and original spectrum beta-lactamases TEM-1 and TEM-190. In one isolate, the CarbaNP test was negative, the $\mathrm{mCIM}$ was positive, and OXA-48 carbapenemase was detected. Phylogroup A was the most frequent $(n=9)$ followed by $B 2$, E and $F(n=2$, respectively), and through PFGE, no clonal relationship was observed. Eleven different sequence types (ST) were found, with ST10 high-risk clone being the most frequent $(n=4)$. Seventy-two percent of the isolates were from health care-associated infections; the mortality rate was $11.1 \%$.

Conclusions: This is the first report in Mexico of E. coli producing CMY isolated from paediatric patients, demonstrating a frequency of $4.5 \%$. In addition, this is the first finding of E. coli ST10 with CMY-2 and OXA-48.

Keywords: CMY beta-lactamases, AmpC, E. coli, Paediatrics, Mexico

\footnotetext{
*Correspondence: aaquinoa@pediatria.gob.mx

${ }^{1}$ Molecular Microbiology Laboratory, Instituto Nacional de Pediatria, Insurgentes Sur 3700C, Insurgentes Cuicuilco, Coyoacan, 04530 Mexico City, Mexico

Full list of author information is available at the end of the article
}

\section{Background}

Of the family Enterobacteriaceae, Escherichia coli is one of the main causative agents of infections, both in the hospital environment and in the community [1]. original author(s) and the source, provide a link to the Creative Commons licence, and indicate if changes were made. The images or other third party material in this article are included in the article's Creative Commons licence, unless indicated otherwise in a credit line to the material. If material is not included in the article's Creative Commons licence and your intended use is not permitted by statutory regulation or exceeds the permitted use, you will need to obtain permission directly from the copyright holder. To view a copy of this licence, visit http://creativecommons.org/licenses/by/4.0/. The Creative Commons Public Domain Dedication waiver (http://creativeco mmons.org/publicdomain/zero/1.0/) applies to the data made available in this article, unless otherwise stated in a credit line to the data. 
In $E$. coli, the main mechanism of resistance to betalactam antibiotics is the production of beta-lactamases [2]. Among the different types of beta-lactamases, the AmpC-type has emerged as an important group of enzymes [3]. AmpC types are present in the chromosome of some enterobacteria but can pass to mobile genetic elements, such as plasmids, and be transferred horizontally between different species. These enzymes confer resistance to oxyimino-cephalosporins (ceftazidime, cefotaxime), cephamycins (cefoxitin) and monobactams (aztreonam). However, this spectrum of hydrolysis can be extended and affect fourth generation cephalosporins (4GC) (cefepime) [4]. Eight families of plasmid AmpC have been described based on differences in the amino acid sequence: CMY (cephamycin), FOX (cefoxitin), ACC (Ambler class C), LAT (latamoxef), MIR (Miriam hospital in Providence), ACT (AmpC type), MOX (moxalactam), and DHA (Dhahran hospital in Saudi Arabia) [3, 5]. Of these groups, CMY-2 is the most common type in E. coli and has been reported in Asia, Europe and North America [6-9]. In 2014, as part of the International Network for Optimal Resistance Monitoring (INFORM) program, 2,813 E. coli isolates were collected in 69 hospital centres in the USA, and CMY-2 was reported in 74 isolates (2.6\%) [10]. In the Study for Monitoring Antimicrobial Resistance Trends (SMART) performed in 12 countries of the Asia-Pacific region in the 20082014 period, CMY-2 was reported in $1739 \mathrm{E}$. coli isolates at a frequency of $10.2 \%(\mathrm{n}=178)$ [11]. There have been reports of CMY-2 in Latin America: Argentina (0.9\%), Colombia (3.5\%) and Brazil (0.5\%) [12-14]. In Mexico, only one study has reported E. coli producing CMY, causing a urinary tract infection in an adult patient [15]. Other studies have reported the presence of these enzymes in isolates obtained from animal origin, such as dogs $(11.3 \%)$, sheep $(0.64 \%)$ and turtles (9.8\%) [16-18]. However, there is no information on the molecular or epidemiological characteristics of $E$. coli isolates producing CMY-type beta-lactamases in the Mexican paediatric population.

The aim of this study was to detect CMY-type betalactamases in isolates from $E$. coli obtained from paediatric patients attended at a tertiary care hospital.

\section{Methods}

\section{Study site}

The National Institute of Paediatrics (INP) is a tertiary care and teaching hospital in Mexico City with 235 beds and 40 medical subspecialties. In 2018, the INP had 6072 discharges.

\section{Isolates}

In total, 404 non-duplicate $3 \mathrm{GC}$ and/or $4 \mathrm{GC}$ resistant E. coli isolates were collected from paediatric patients ( 0 to $<18$ years) from the National Institute of Paediatrics (INP) over a 2-years period (February 2013January 2015). These isolates were obtained from various clinical samples causing confirmed infections. We reviewed the medical files in order to collect clinical information such as: date of admission, gender, age, antibiotic treatments, among others. An infection was considered HAI if it appeared on or after the 3rd day of admission, according to the definitions of the Centers for Disease Control and Prevention (CDC) [19]. The strains were identified using the Phoenix Automated Microbiology System ${ }^{\circledR}$ (Becton Dickinson, New Jersey, USA).

\section{Antimicrobial susceptibility profiles of $E$. coli isolates}

The susceptibility profile of the isolates was determined using the Phoenix ${ }^{\circledR}$ automated system (Becton Dickinson, New Jersey, USA). The tested antibiotics were ceftriaxone (CRO), ceftazidime (CAZ), cefepime (FEP), imipenem (IMP), meropenem (MEM) and ertapenem (ETP). The minimum inhibitory concentration (MIC) to cefoxitin was determined using the broth microdilution method following the guidelines of M07 of the Clinical and Laboratory Standards Institute [20]. The interpretation of the results was performed in accordance with CLSI document M100 [21].

\section{Molecular detection of $b / a_{\mathrm{CMY}}$ and other beta-lactamase genes}

Total DNA extraction was performed using the QIAamp ${ }^{\circledR}$ DNA Mini Kit (QIAGEN, Hilden, Germany) following the manufacturer's instructions. Detection of $b l a_{\mathrm{CMY}}$ and other beta-lactamases $\left(b l a_{\mathrm{CTX}-\mathrm{M}-1}, b l a_{\mathrm{CTX}-\mathrm{M}-2}, b l a_{\mathrm{CTX}-\mathrm{M}-9}\right.$, $b l a_{\mathrm{CTX}-\mathrm{M} 8 / 25}, b l a_{\text {TEM }}$ and $\left.b l a_{\text {SHV }}\right)$ was performed by endpoint monoplex PCR. For the isolates with decreased susceptibility or resistance to carbapenems, carbapenemase genes were amplified; multiplex PCR $\left(b l a_{\mathrm{VIM}}\right.$, $b l a_{\mathrm{IMP}}$ and $\left.b l a_{\mathrm{KPC}}\right)$, and $b l a_{\mathrm{NDM}}, b l a_{\mathrm{OXA}-48}$ and $b l a_{\mathrm{GES}}$ were individually amplified. We used previously published primers [22-25]. The reaction was performed in an AB9700 thermocycler (Applied Biosystems, Foster City, CA, USA) using AmpliTaq Gold ${ }^{\circledR} 360$ MasterMix (Applied Biosystems, Foster City CA, USA). The fragments obtained were purified with a QIAquick PCR purification kit (QIAGEN, Hilden, Germany) and sequenced on a 3500 XL system (Applied Biosystems, Foster City, CA, USA). The sequences were analysed with the blastn program $[26,27]$, and multiple alignments were made 
with the BioEdit v7.2 program (Ibis Biosciences, Carlsbad CA, USA) to determine the beta-lactamase subtype.

\section{Phenotypic tests for AmpC, ESBL and carbapenemases}

The phenotypic detection of AmpC enzymes was performed with double-disc synergy using ceftazidime disks (Becton Dickinson, New Jersey, USA) alone and in combination with cloxacillin $(20 \mathrm{mg} / \mathrm{mL})$ and boronic acid $(20 \mathrm{mg} / \mathrm{mL}$ ) (Sigma Aldrich, Milwaukee, WI). A test was considered positive if there was an increase in the inhibition diameter $\geq 5 \mathrm{~mm}$ of the ceftazidime in the presence of cloxacillin or boronic acid compared to the diameter of the ceftazidime without inhibitor [28].

The phenotypic detection of ESBL was performed by the combined disc method, using disks of cefotaxime $(30 \mu \mathrm{g})$ and ceftazidime $(30 \mu \mathrm{g})$ alone and in combination with clavulanic acid $(30 \mu \mathrm{g} / 10 \mu \mathrm{g})$ (Becton Dickinson, New Jersey, USA) following the guidelines of the CLSI The presence of ESBL was confirmed by an increase of $>5 \mathrm{~mm}$ in the diameter of the zone of inhibition for any agent tested in combination with clavulanic acid compared with the diameter of the zone of inhibition for the agent alone [21].

Isolates with decreased susceptibility or resistance to carbapenems (IMP, MEM, ETP) were tested for carbapenemases production using CarbaNP and $\mathrm{mCIM}$ according to the guidelines of the CLSI [21].

\section{Molecular typing}

The phylogenetic group of the isolates was obtained with the Clermont method [29]. The clonal relationship was determined using PFGE following the protocol for E. coli O157:H7 from PulseNet (CDC, Atlanta, GA) [30]. The Salmonella enterica serotype Braenderup ATCC BAA664 strain was used as a molecular size marker. The band patterns were interpreted using Tenover criteria [31]. The ImageLab v5.2.1 program (Bio-Rad, Hercules, CA, USA) was used to create a $0 / 1$ matrix, and DendroUpGMA (https://genomes.urv.cat/UPGMA/) and MEGA-X programs [32] were used to construct the dendrogram.

For detection of the E. coli ST131-O25b clone, $\operatorname{trp} A$, $p a b B$ and $r f b$ genes were amplified [33].

The MLST technique was performed by amplifying seven housekeeping genes ( $a d k$, fum $C$, gyrB $, i c d, m d h$, purA and $r e c A$ ) using primers and conditions previously reported [34]. The sequences were analysed using the database available at https://enterobase.warwick.ac.uk/ species/index/ecoli.

\section{Results}

Detection of bla $_{\mathrm{CMY}}$ and other beta-lactamase genes Of the $404 \mathrm{E}$. coli isolates, CMY-type beta-lactamases were detected in 18 (4.5\%). The susceptibility profile of the isolates with CMY was FEP 22.3\% ( $\mathrm{n}=4)$, IMP 94.4\% $(\mathrm{n}=17)$, MEM 94.4\% $(\mathrm{n}=17)$ and ETP $77.7 \%(\mathrm{n}=14)$; three isolates were intermediate to CAZ, one was to FOX and none was susceptible to ceftriaxone. The allelic variants found were CMY-2 $(n=14)$ and CMY-42 $(n=4)$. In 15 isolates, coexistence with other beta-lactamase genes was observed such as CTX-M-15 ESBL, TEM-1 and TEM-190 OSBL and OXA-48 carbapenemase. The genes $b l a_{\mathrm{SHV}}, b l a_{\mathrm{CTX}-\mathrm{M}-2}, b l a_{\mathrm{CTX}-\mathrm{M}-9}, b l a_{\mathrm{CTX}-\mathrm{M}-8 / 25}$, $b l a_{\mathrm{GES}}, b l a_{\mathrm{KPC}}, b l a_{\mathrm{NDM}}, b l a_{\mathrm{VIM}}, b l a_{\mathrm{IMP}}$ were not detected (Table 1).

\section{Phenotypic tests}

The AmpC phenotypic production test was positive in 11 isolates with cloxacillin (61.1\%) and 15 isolates with boronic acid (83.3\%); 13 isolates were positive for the ESBL confirmatory phenotypic test. Of the four strains of $E$. coli with decreased susceptibility to ertapenem, one was negative for the CarbaNP test and positive for mCIM (Ec445). The remaining three strains were negative for both tests (Ec24, Ec668 and Ec686) (Table 1).

\section{Molecular typing}

Regarding molecular typing in the CMY-producing $E$. coli isolates, phylogroup A was the most frequent (six isolates with CMY-2 and three with CMY-42) (Table 1). Using PFGE, no clonal relationship was observed between isolates, two of which were non-typable by this technique (Fig. 1). Eleven different STs were found: ST10 $(\mathrm{n}=5)$, three isolates with CMY-2 and two with CMY42 (Table 1). One isolate corresponded to ST131-O25b clone (Ec223). The known high-risk clones ST10, ST69, ST405 and ST648 were detected. It was not possible to assign the $\mathrm{ST}$ in two isolates.

Regarding epidemiological analysis of patients with CMY-producing E. coli, 83\% had comorbidities, 56\% were male, and the median age was 3.5 years (range 0.6-14 years). Seventy-two percent of the isolates were from health care-associated infections. The main sample was urine (50\%), followed by secretion (wound and intraabdominal, 22.2\%) and blood (16.7\%). Eleven patients received $3 \mathrm{GC}$ as empirical treatment. Ten patients received carbapenems as definitive treatment, and just two received cefepime. The largest number of isolates was reported in 2014 $(n=10)$. Two patients died from septic shock (Table 2).

\section{Discussion}

This study represents the first report in Mexico of E. coli isolates producing CMY in the paediatric population. Previous studies in our country have documented the presence of these enzymes only in adult patients and animals [16-18]. In this study, the frequency of $b l a_{\mathrm{CMY}}$ in $E$. 


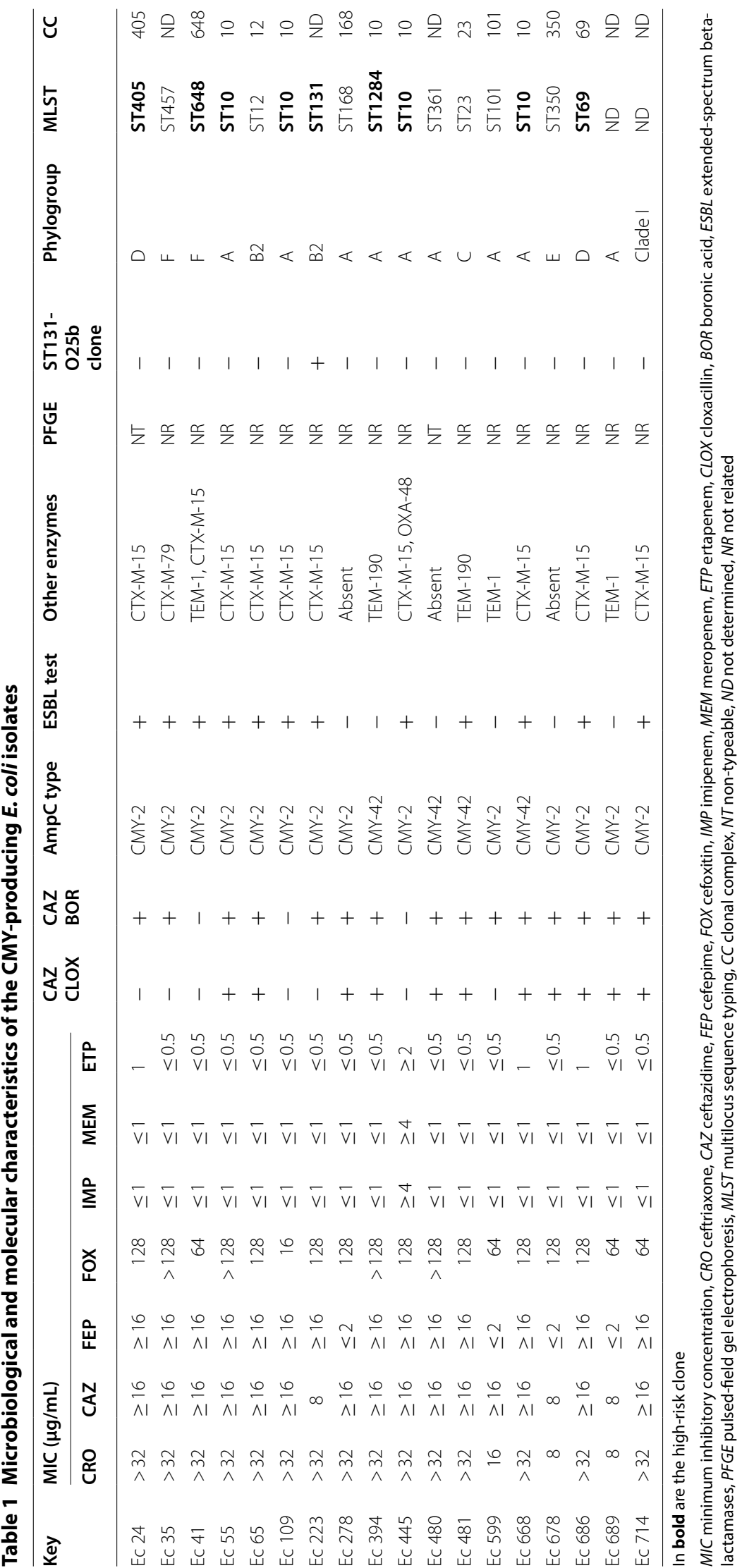




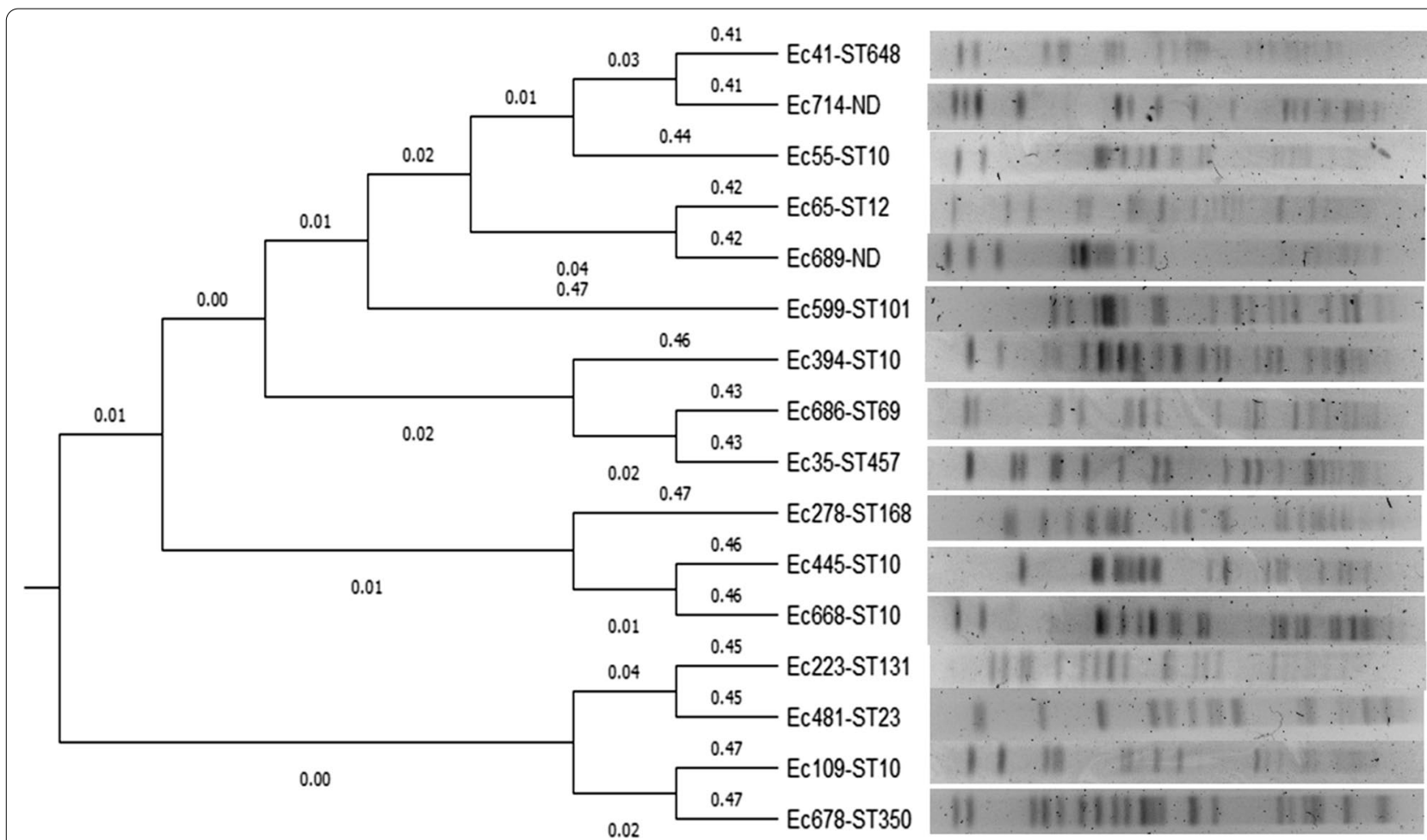

Fig. 1 Dendrogram obtained by UPGMA (unweighted pair group method with arithmetic mean). Different pulsotypes of the CMY producing E. coli isolates are shown

coli was $4.5 \%$, like that reported in three paediatric hospitals in Chicago, USA. (4.4\%) [35]. Another study in the same country found $27.9 \%$ of E. coli isolates with CMY [36]. In contrast, in Chinese children, CMY was reported only in $1 \%$ of isolates [37]. Although ESBL, specifically CTX-M-15, are predominant in E. coli, in recent years, there have been an increase in reports of strains producing AmpC, mainly CMY.

CMY-2 is the most frequent AmpC-type beta-lactamase in $E$. coli, according to reports from countries, such as Spain and Japan [38, 39]. In our study, this subtype was present in $77.8 \%$ of isolates with CMY, and the rest was CMY-42. This variant has been described mainly in India and Egypt [40, 41]. The selection pressure has caused the emergence of variants with hydrolytic activity towards extended-spectrum cephalosporins.

Resistance to cefoxitin, together with sensitivity to cefepime, has been used as a marker of AmpC-type enzyme production. However, in this study, an isolate with CMY presented intermediate sensitivity to cefoxitin, and 14 (78\%) were resistant to cefepime. Twelve isolates $(67 \%)$ were positive for the ESBL phenotypic test, higher than reported in the literature (9.9-36\%) [42], which explains the resistance to cefepime. In two isolates with a negative ESBL test (Ec394, Ec480), CMY-42 could have been responsible for resistance to cefepime.
The detection of these enzymes is complicated due to the simultaneous production of ESBL and AmpC in an isolate, which makes difficult the interpretation of the antimicrobial susceptibility test.

Due to the lack of standardized methods for the phenotypic detection of these enzymes, their prevalence may be underestimated. One of the phenotypic methods for this purpose is based on the use of cloxacillin and boronic acid as inhibitors with a specificity of $50-90 \%[43,44]$. In this study, boronic acid was a better inhibitor (83.3\%) than cloxacillin (61.1\%). In contrast, other reports have indicated greater sensitivity using cloxacillin (77-94\%) $[28,41]$. However, three isolates with CMY were negative for the phenotypic test with both inhibitors. Given the limitations of phenotypic tests and the lack of standardized methods by international guidelines, such as CLSI or EUCAST, molecular methods, such as PCR, should be considered for the detection of these enzymes.

The presence of ESBL and CMY was observed in 11 isolates (61.1\%), all with CTX-M group enzymes, mainly CMY-2 with CTX-M-15 ( $\mathrm{n}=9)$. In Japan, CTX-M-15 was detected with CMY in $72 \%$ of E. coli strains [45]. In one isolate (Ec394) with a positive ESBL test, only TEM190 was detected, which is not an ESBL, thus the ESBL profile may have been due to another enzyme that was not determined in this work. Although the frequency of 


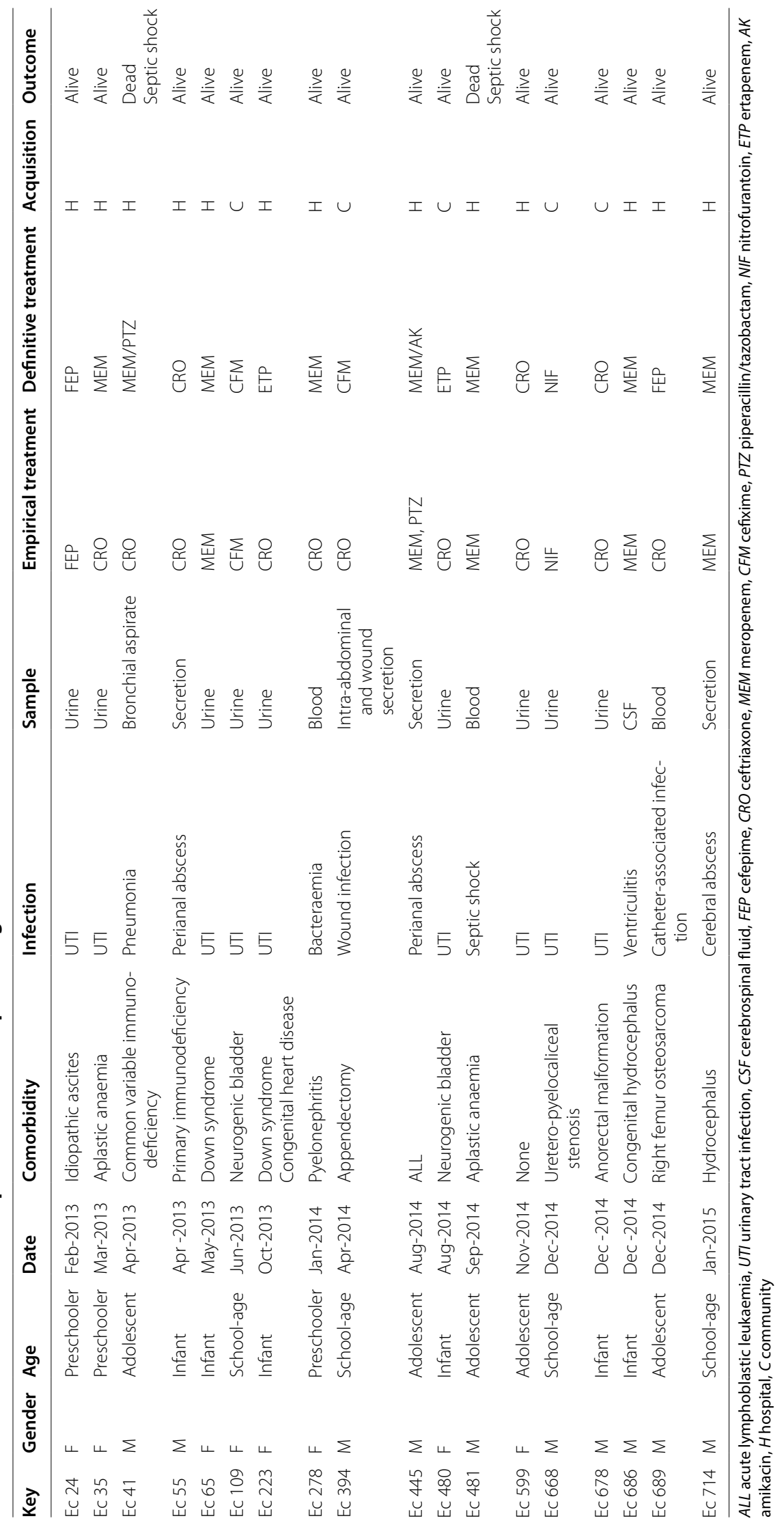


CMY is lower than that of ESBL, it is clinically significant because when combined with the loss of porins (OmpC, $\mathrm{OmpF}$ ), it can confer resistance to carbapenems, one of the last-line antibiotics for the treatment of infections [46]. On the other hand, CMY enzymes have relevance in resistance to recently introduced antimicrobials, for instance in a study carried out in centers in USA; two $E$. coli isolates were found, in which genes encoding the CTX-M-15 and CMY-2-like beta-lactamases coexisted; both isolates were resistant to ceftolozane-tazobactam with MIC $64 \mu \mathrm{g} / \mathrm{mL}$ and $128 \mu \mathrm{g} / \mathrm{mL}$, respectively [47]. The existence of these two mechanisms of resistance in the same isolate can complicate the interpretation of the antibiogram and, consequently, the proper selection of antimicrobial treatment.

In one isolate (Ec445), co-production of CMY-2 with the carbapenemase OXA- 48 was detected, which represents the first report of this coexistence in Mexico. This combination was reported in the USA, in isolates obtained from dogs and cats [48]. In other studies, the simultaneous production of CMY with other carbapenemases has been reported. CMY-42 has been described in coexistence with NMD-5 in Italy [49] and Spain [50], and the presence of CMY-42 with NDM-1 and CTX-M-15 has been reported in China [51] and CMY-42 with OXA181 in India [52]. The simultaneous production of different beta-lactamases decreases the therapeutic options for the treatment of infections.

In Malaysia and the USA, patients colonized by CMY2-producing $E$. coli have been described at frequencies of $6.4 \%$ and $24 \%$, respectively $[53,54]$. In the Netherlands, it was reported that $1.1 \%$ of adult carriers were colonized by E. coli with CMY-2 [55]. In Mozambique, E. coli was detected with CMY-2 in $20 \%$ of university students [56]. The presence of these enzymes has also been documented in dogs and cats, with frequencies ranging from 3.8 to $85 \%[57,58]$. In addition, the coexistence of CMY-2 with the $m c r-1$ gene has been detected in poultry, in Germany [59] and in food-producing animals, in Portugal [60]. These studies indicate that people and animals are reservoirs for the dissemination of $E$. coli strains with this type of enzyme or can transfer resistance genes to other species.

Fifty percent of $E$. coli isolates with CMY were classified into commensal phylogroup A (33.3\% CMY-2, $16.7 \%$ CMY-42), in contrast to that reported in Spain, where pathogenic phylogroup B2 was the most frequent among E. coli with CMY-2 [61]. Other studies in New Zealand and the USA, have reported D as the main phylogroup [62, 63]. In France, a higher frequency was reported in commensal phylogroups (A, B1 and C) than in pathogenic phylogroups (B2, D and F) [64]. Thus, CMY presents a heterogeneous distribution among phylogroups, and commensal E. coli can acquire resistance genes as well as the capacity to cause infections.

There are reports indicating that the dissemination of E. coli isolates producing CMY is non-clonal $[61,62]$. In this study, 11 different STs were obtained, and the main was ST10, which is considered a high-risk clone. This ST has been reported in isolates from humans and in chicken meat in Germany [59]. High-risk clones ST69, ST405 and ST648 were also detected. ST69 with CMY-2 has been described in dairy cows in the Czech Republic [65] and in an E. coli strain with $m c r-1$ obtained from a urinary tract infection case, in England [66]. ST405 and ST648 with CMY-2 have been described in strains isolated from pets in the USA coexisting with OXA-48 [48]. E. coli ST457 with CMY-2 has been reported in molluscs and poultry in Brazil $[67,68]$ and in an isolate obtained from a paediatric patient in the USA [69]. E. coli ST23 with CMY-2 has been detected in chicken faeces and meat in Denmark [70], and a strain of $E$. coli ST361 with CMY-42 from the urinary tract was reported in India [40]. In this study, these two clones (Ec480-ST361 and Ec481-ST23) had CMY-42. On the other hand, E. coli ST12 with CMY-2 was reported in poultry in Italy [71], E. coli ST350 in chicken carcasses in Brazil [72], E. coli ST101 with CMY-42 was described in a paediatric patient with bacteraemia [69] and E. coli ST1284 with CMY-2 in a dog with skin and soft tissue infection [73]. Due to the diversity of ST found in this study and those reported in other studies, the dissemination of CMY enzymes seems not to be related to a specific lineage of $E$. coli, but rather to the transfer of mobile genetic elements. Likewise, there are several reservoirs for these beta-lactamases, such as animals, food and aquatic environments.

In this study, only one isolate with CMY-2 belonged to the E. coli $\mathrm{ST} 131-\mathrm{O} 25 \mathrm{~b}$ clone, which is responsible for the global dissemination of CTX-M-15. This ST with CMY has been reported in strains that cause urinary tract infections and bacteraemia $[62,74,75]$ and in strains obtained from chickens in Germany [59]. Although there are few reports of E. coli ST131-O25b with CMY, it is important to surveillance the distribution of this clone due to its epidemic potential.

Different risk factors associated with the acquisition of $E$. coli with $\mathrm{AmpC}$, such as comorbidities, previous use of antimicrobials, use of medical devices, urinary tract abnormalities and prolonged hospital stay have been described in adult patients [76, 77] In the current study, most of the patients had comorbidities and had previously received broad-spectrum antimicrobials (3GC, 4GC and carbapenems). Three patients had urinary tract pathologies, which could have caused greater susceptibility to urinary tract infections. Two patients 
died from septic shock derived from CMY-producing E. coli infections.

\section{Conclusions}

This study represents the first report of E. coli producing CMY in the paediatric population in Mexico, with a frequency of $4.5 \%$. The dissemination of these enzymes in our study was associated with high clonal diversity. A high proportion of $E$. coli producing CMY also harbour ESBL enzymes. The difficulty of detecting CMY only by phenotypic tests, makes the use of molecular techniques essential.

Due to the emergence of high-risk $E$. coli clones in our hospital, it is necessary to maintain an epidemiological surveillance programme that allows the timely detection of these strains to prevent outbreaks.

In addition, this is the first report of E. coli ST10 with CMY-2 and OXA-48 in Mexico.

\begin{abstract}
Abbreviations
ESBL: Extended-spectrum beta-lactamases; OSBL: Original spectrum beta-lactamases;; mCIM: Modified carbapenem inhibition method; PFGE: Pulsed-field gel electrophoresis; MLST: Multilocus sequence typing; 3GC: Third generation cephalosporins; 4GC: Fourth generation cephalosporins; CMY: Cephamycin; FOX: Cefoxitin; ACC: Ambler class C; LAT: Latamoxef; MIR: Miriam hospital in Providence; ACT: AmpC type; MOX: Moxalactam; DHA: Dhahran hospital in Saudi Arabia; MIC: Minimum inhibitory concentration; UPGMA: Unweighted pair group method with arithmetic mean.
\end{abstract}

\section{Authors' contributions}

AAA and ADC designed the study; JMV and AAA performed the experiments; ADC and YCC collected the microbiological and epidemiological data; JMV and AAA analysed the data and wrote the first draft of the manuscript. All authors read and approved the final manuscript.

\section{Funding}

This work was supported by CONACYT through the projects FOSSIS-2012-1-181041 and FOSSIS-2017-1-289537 and by the fiscal resources of the A-modality INP-2019 and INP-2020 (Recurso Fiscal Modalidad A del Instituto Nacional de Pediatria 2019-2020) under registration INP-2018/017. They had no role in the design of the study and collection, analysis, and interpretation of data and in writing the manuscript.

\section{Availability of data and materials}

All the data supporting our findings is contained within the manuscript.

\section{Ethics approval and consent to participate}

This study was approved by the Research and Ethics Committees of the INP (IRB: 00008064, IRB: 00008065 Registry Number 066/2013). The ethics committee exempted informed consent because the isolates were obtained as part of standard patient care.

\section{Competing interests}

The authors declare that they have no competing interests.

\section{Author details}

${ }^{1}$ Molecular Microbiology Laboratory, Instituto Nacional de Pediatria, Insurgentes Sur 3700C, Insurgentes Cuicuilco, Coyoacan, 04530 Mexico City, Mexico. ${ }^{2}$ Department of Paediatric Infectious Diseases, Instituto Nacional de Pediatria, Mexico City, Mexico. ${ }^{3}$ Clinical Bacteriology Laboratory, Instituto Nacional de Pediatria, Mexico City, Mexico.
Received: 25 May 2020 Accepted: 22 October 2020

Published online: 29 October 2020

\section{References}

1. Allocati N, Masulli M, Alexeyev MF, Di llio C. Escherichia coli in Europe: an overview. Int J Environ Res Public Health. 2013;10:6235-54.

2. Bajaj P, Singh NS, Virdi JS. Escherichia coli beta-lactamases: what really matters. Front Microbiol. 2016;7:417.

3. Jacoby GA. AmpC beta-Lactamases. Clin Microbiol Rev. 2009;22:161-82.

4. Powers RA. Structural and functional aspects of extended-spectrum AmpC cephalosporinases. Curr Drug Targets. 2016;17:1051-60.

5. Philippon A, Arlet G, Jacoby GA. Plasmid-determined AmpC-type betalactamases. Antimicrob Agents Chemother. 2002;46:1-11.

6. Pitout JDD. Extraintestinal pathogenic Escherichia coli: a combination of virulence with antibiotic resistance. Front Microbiol. 2012;3:9.

7. Li Y, Li Q, Du Y, Jiang X, Tang J, Wang J, et al. Prevalence of plasmid-mediated AmpC beta-lactamases in a Chinese university hospital from 2003 to 2005: first report of CMY-2-type AmpC beta-lactamase resistance in China. J Clin Microbiol. 2008;46(4):1317-21.

8. Woodford N, Reddy S, Fagan EJ, Hill RL, Hopkins KL, Kaufmann ME, et al. Wide geographic spread of diverse acquired AmpC beta-lactamases among Escherichia coli and Klebsiella spp. in the UK and Ireland. J Antimicrob Chemother. 2007;591:102-5.

9. Deshpande LM, Jones RN, Fritsche TR, Sader HS. Occurrence of plasmidic AmpC type beta-lactamase-mediated resistance in Escherichia coli: report from the SENTRY Antimicrobial Surveillance Program (North America, 2004). Int J Antimicrob Agents. 2006;28(6):578-81.

10. Castanheira M, Mendes RE, Jones RN, Sader HS. Changes in the frequencies of $\beta$-lactamase genes among Enterobacteriaceae isolates in U.S. hospitals, 2012 to 2014: activity of ceftazidime-avibactam tested against $\beta$-lactamase-producing isolates. Antimicrob Agents Chemother. 2016;60:4770-7.

11. Jean SS, Hsueh PR, SMART Asia-Pacific Group. Distribution of ESBLS, AmpC $\beta$-lactamases and carbapenemases among Enterobacteriaceae isolates causing intra-abdominal and urinary tract infections in the Asia-Pacific region during 2008-14: results from the Study for Monitoring Antimicrobial Resistance Trends (SMART). J Antimicrob Chemother. 2017;72:166-71.

12. Cejas D, Fernández Canigia L, Quinteros M, Giovanakis M, Vay C, Lascialandare S, et al. Plasmid-encoded AmpC (pAmpC) in Enterobacteriaceae: epidemiology of microorganisms and resistance markers. Rev Argent Microbiol. 2012;44:182-6.

13. Leal AL, Cortes JA, Arias G, Ovalle MV, Saavedra SY, Buitrago G, et al. Emergencia de fenotipos resistentes a cefalosporinas de tercera generacion en Enterobacteriaceae causantes de infeccion del tracto urinario de inicio comunitario en hospitales de Colombia. Enferm Infecc Microbiol Clin. 2013;31:298-303.

14. Rocha DA, Campos JC, Passadore LF, Sampaio SC, Nicodemo AC, Sampaio $J$ L. Frequency of plasmid-mediated AmpC $\beta$-lactamases in Escherichia coli isolates from urine samples in São Paulo, Brazil. Microb Drug Resist. 2016;22:321-7.

15. Belmont-Monroy L, Ribas-Aparicio RM, Navarro-Ocaña A, ManjarrezHernández HÁ, Gavilanes-Parra S, Aparicio-Ozores G, et al. Characterization of Escherichia coli causing community acquired urinary tract infections in Mexico City. Diagn Microbiol Infect Dis. 2017;87:193-5.

16. Rocha-Gracia RC, Cortes-Cortes G, Lozano-Zarain P, Bello F, MartinezLaguna Y, Torres C. Faecal Escherichia coli isolates from healthy dogs harbour CTX-M-15 and CMY-2 beta-lactamases. Vet J. 2015;203:315-9.

17. Aguilar-Montes de Oca S, Talavera-Rojas M, Soriano-Vargas E, Barba-Leon J, Vazquez-Navarrete J. Determination of extended spectrum betalactamases/AmpC beta-lactamases and plasmid-mediated quinolone resistance in Escherichia coli isolates obtained from bovine carcasses in Mexico. Trop Anim Health Prod. 2015:47:975-81.

18. Cortés-Cortés G, Lozano-Zarain P, Torres $C$, Castañeda M, Moreno Sánchez G, Alonso CA, et al. Detection and molecular characterization of Escherichia coli strains producers of extended-spectrum and CMY-2 type beta-lactamases, isolated from turtles in Mexico. Vector Borne Zoonotic Dis. 2016;16:595-603. 
19. Centers of Diseases Control and Prevention. CDC/NHSN surveillance definitions for specific types of infections. Atlanta: Centers of Diseases Control and Prevention; 2014. https://www.cdc.gov/nhsn/PDFs/pscMa nual/17pscNosInfDef_current.pdf.

20. CLSI. Methods for dilution antimicrobial susceptibility tests for bacteria that grow aerobically. CLSI standard M07. 11th ed. Wayne: Clinical and Laboratory Standards Institute; 2018.

21. CLSI. Performance standards for antimicrobial susceptibility testing. CLS supplement M100. 29th ed. Wayne: Clinical and Laboratory Standards Institute; 2019.

22. Alcantar-Curiel D, Tinoco JC, Gayosso C, Carlos A, Daza C, Perez-Prado $M C$, et al. Nosocomial bacteremia and urinary tract infections caused by extended-spectrum beta -lactamase-producing Klebsiella pneumoniae with plasmids carrying both SHV-5 and TLA-1 genes. Clin Infect Dis. 2004;38:1067-74.

23. Dallenne C, da Costa A, Decré D, Favier C, Arlet G. Development of a set of multiplex PCR assays for the detection of genes encoding important $\beta$-lactamases in Enterobacteriaceae. J Antimicrob Chemother. 2010;65:490-5.

24. Nordmann P, Poirel L, Carrër A, Toleman MA, Walsh TR. How to detect NDM-1 producers. J Clin Microbiol. 2011;49(2):718-21.

25. Brink AJ, Coetzee J, Corcoran C, Clay CG, Hari-Makkan D, Jacobson RK, et al. Emergence of OXA-48 and OXA-181 Carbapenemases among Enterobacteriaceae in South Africa and evidence of in vivo selection of colistin resistance as a consequence of selective decontamination of the gastrointestinal tract. J Clin Microbiol. 2013;51:369-72.

26. Morgulis A, Coulouris G, Raytselis Y, Madden TL, Agarwala R, Schäffer AA Database indexing for production MegaBLAST searches. Bioinformatics. 2008;24:1757-64.

27. Zhang Z, Schwartz S, Wagner L, Miller W. A greedy algorithm for aligning DNA sequences. J Comput Biol. 2000;7:203-14.

28. Reuland EA, Hays JP, de Jongh DM, Abdelrehim E, Willemsen I, Kluytmans $\mathrm{JA}$, et al. Detection and occurrence of plasmid-mediated AmpC in highly resistant gram-negative rods. PLoS ONE. 2014;9:e91396.

29. Clermont O, Christenson JK, Denamur E, Gordon DM. The Clermont Escherichia coli phylo-typing method revisited: improvement of specificity and detection of new phylo-groups. Environ Microbiol Rep. 2013;5:58-65.

30. Ribot EM, Fair M, Gautom R, Cameron DN, Hunter SB, Swaminathan B, et al. Standardization of pulsed-field gel electrophoresis protocols for the subtyping of Escherichia coli O157:H7, Salmonella, and Shigella for PulseNet. Foodborne Pathog Dis. 2006;3:59-67.

31. Tenover FC, Arbeit RD, Goering RV, Mickelsen PA, Murray BE, Persing DH, et al. Interpreting chromosomal DNA restriction patterns produced by pulsed-field gel electrophoresis: criteria for bacterial strain typing. J Clin Microbiol. 1995;33:2233-9.

32. Kumar S, Stecher G, Li M, Knyaz C, Tamura K. MEGA X: molecular evolutionary genetics analysis across computing platforms. Mol Biol Evol. 2018;35:1547-9.

33. Clermont O, Lavollay M, Vimont S, Deschamps C, Forestier C, Branger C, et al. The CTX-M-15-producing Escherichia coli diffusing clone belongs to a highly virulent B2 phylogenetic subgroup. J Antimicrob Chemother. 2008:61:1024-8

34. Wirth T, Falush D, Lan R, Colles F, Mensa P, Wieler LH, et al. Sex and virulence in Escherichia coll: an evolutionary perspective. Mol Microbiol. 2006;60:1136-51.

35. Logan LK, Hujer AM, Marshall SH, Domitrovic TN, Rudin SD, Zheng X, et al. Analysis of $\beta$-lactamase resistance determinants in Enterobacteriaceae from Chicago children: a multicenter survey. Antimicrob Agents Chemother. 2016;60:3462-9.

36. Zerr DM, Weissman SJ, Zhou C, Kronman MP, Adler AL, Berry JE, et al. The molecular and clinical epidemiology of extended-spectrum cephalosporin- and carbapenem-resistant Enterobacteriaceae at 4 US pediatric hospitals. J Pediatric Infect Dis Soc. 2017;6:366-75.

37. Ding H, Yang Y, Lu Q, Wang Y, Chen Y. The prevalence of plasmid-mediated AmpC $\beta$-lactamases among clinical isolates of Escherichia coli and Klebsiella pneumoniae from five children's hospitals in China. Eur J Clin Microbiol Infect Dis. 2008;27:915-21.

38. Matsumura Y, Nagao M, Iguchi M, Yagi T, Komori T, Fujita N, et al. Molecular and clinical characterization of plasmid-mediated AmpC $\beta$-lactamase-producing Escherichia coli bacteraemia: a comparison with extended-spectrum $\beta$-lactamase-producing and non-resistant $E$. coli bacteraemia. Clin Microbiol Infect. 2013;19:161-8.

39. Miró E, Agüero J, Larrosa MN, Fernández A, Conejo MC, Bou G, et al. Prevalence and molecular epidemiology of acquired AmpC $\beta$-lactamases and carbapenemases in Enterobacteriaceae isolates from 35 hospitals in Spain. Eur J Clin Microbiol Infect Dis. 2013;32:253-9.

40. Ingti B, Saikia P, Paul D, Maurya AP, Dhar Chanda D, Chakravarty A, et al. Occurrence of blaCMY-42 on an Incl1 plasmid in multidrug-resistant Escherichia coli from a tertiary referral hospital in India. J Glob Antimicrob Resist. 2018;14:78-82.

41. Helmy MM, Wasfi R. Phenotypic and molecular characterization of plasmid mediated AmpC $\beta$-lactamases among Escherichia coli, Klebsiella spp., and Proteus mirabilis isolated from urinary tract infections in Egyptian hospitals. Biomed Res Int. 2014;2014:171548.

42. Kazi M, Ajbani K, Tornheim JA, Shetty A, Rodrigues C. Multiplex PCR to detect PAmpC $\beta$-lactamases among Enterobacteriaceae at a tertiary care laboratory in Mumbai, India. Microbiology. 2019;165:246-50.

43. Caliskan E, Say Coskun US, Dulger G, Kilincel O, Ankarali H, Sahin I. Investigation of plasmid mediated AmpC beta-lactamases in Escherichia coli and Klebsiella pneumoniae isolates by phenotypic and genotypic. J Pak Med Assoc. 2019;69:834-9.

44. Tamma PD, Doi Y, Bonomo RA, Johnson JK, Simner PJ, Antibacterial Resistance Leadership Group. A primer on AmpC beta-lactamases: necessary knowledge for an increasingly multidrug-resistant world. Clin Infect Dis. 2019;69:1446-55.

45. San N, Aung MS, Urushibara N, San T, Maw WW, Lwin MM, et al. Genetic Diversity of CMY beta-lactamase genes in clinical isolates of Escherichia coli in Myanmar: identification of three novel types and updated phylogenetic classification of bla cur. Microb Drug Resist. 2020;26:497-504.

46. Chang YT, Siu LK, Wang JT, Wu TL, Chen YH, Chuang YC, et al. Resistance mechanisms and molecular epidemiology of carbapenemnonsusceptible Escherichia coli in Taiwan, 2012-2015. Infect Drug Resist. 2019;12:2113-23.

47. Hirsch EB, Brigman HV, Zucchi PC, Chen A, Anderson JC, Eliopoulos GM, et al. Ceftolozane-tazobactam and ceftazidime-avibactam activity against $\beta$-lactam-resistant Pseudomonas aeruginosa and extended-spectrum $\beta$-lactamase-producing Enterobacterales clinical isolates from U.S. medical centres. J Glob Antimicrob Resist. 2020;22:689-94.

48. Liu X, Thungrat K, Boothe D. Occurrence of OXA-48 Carbapenemase and other $\beta$-lactamase genes in ESBL-producing multidrug resistant Escherichia coli from dogs and cats in the United States, 2009-2013. Front Microbiol. 2016:7:1057.

49. Piazza A, Comandatore F, Romeri F, Pagani C, Mattioni Marchetti V, Brilli M, et al. Detection of ST1702 Escherichia coli blaNDM-5 and blaCMY-42 genes positive isolates from a Northern Italian hospital. New Microbiol. 2018:41:230-1.

50. Pitart C, Solé M, Roca I, Román A, Moreno A, Vila J, et al. Molecular characterization of blaNDM-5 carried on an IncFIl plasmid in an Escherichia coli isolate from a nontraveler patient in Spain. Antimicrob Agents Chemother. 2015;59:659-62.

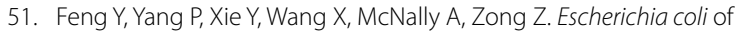
sequence type 3835 carrying bla NDM-1, bla CTX-M-15, bla CMY-42 and bla SHV-12. Sci Rep. 2015;5:12275.

52. Paul D, Babenko D, Toleman MA. Human carriage of cefotaxime-resistant Escherichia coli in North-East India: an analysis of STs and associated resistance mechanisms. J Antimicrob Chemother. 2020;75:72-6.

53. Ho WS, Balan G, Puthucheary S, Kong BH, Lim KT, Tan LK, et al. Prevalence and characterization of multidrug-resistant and extended-spectrum beta-lactamase-producing Escherichia coli from pediatric wards of a Malaysian hospital. Microb Drug Resist. 2012;18:408-16.

54. Suwantarat N, Logan LK, Carroll KC, Bonomo RA, Simner PJ, Rudin SD, et al. The prevalence and molecular epidemiology of multidrug-resistant Enterobacteriaceae colonization in a pediatric intensive care unit. Infect Control Hosp Epidemiol. 2016;37:535-43.

55. Reuland EA, Halaby T, Hays JP, de Jongh DM, Snetselaar HD, van Keulen $\mathrm{M}$, et al. Plasmid-mediated AmpC: prevalence in community-acquired isolates in Amsterdam, the Netherlands, and risk factors for carriage. PLoS ONE. 2015;10:e0113033.

56. Chirindze LM, Zimba TF, Sekyere JO, Govinden U, Chenia HY, Sundsfjord A, et al. Faecal colonization of E. coli and Klebsiella spp. producing 
extended-spectrum beta-lactamases and plasmid-mediated AmpC in Mozambican university students. BMC Infect Dis. 2018;18:244.

57. Wedley AL, Maddox TW, Westgarth C, Coyne KP, Pinchbeck GL, Williams $\mathrm{NJ}$, et al. Prevalence of antimicrobial-resistant Escherichia coli in dogs in a cross-sectional, community-based study. Vet Rec. 2011;168:354.

58. Bortolaia V, Hansen KH, Nielsen CA, Fritsche TR, Guardabassi L. High diversity of plasmids harbouring blaCMY-2 among clinical Escherichia coli isolates from humans and companion animals in the upper Midwestern USA. J Antimicrob Chemother. 2014:69:1492-6.

59. Pietsch M, Irrgang A, Roschanski N, Brenner Michael G, Hamprecht A, Rieber $\mathrm{H}$, et al. Whole genome analyses of CMY-2-producing Escherichia coli isolates from humans, animals and food in Germany. BMC Genom. 2018:19:601.

60. Clemente L, Manageiro V, Correia I, Amaro A, Albuquerque T, Themudo $P$, et al. Revealing mcr-1-positive ESBL-producing Escherichia coli strains among Enterobacteriaceae from food-producing animals (bovine, swine and poultry) and meat (bovine and swine), Portugal, 2010-2015. Int J Food Microbiol. 2019:296:37-42.

61. Alonso N, Miró E, Pascual V, Rivera A, Simó M, Garcia MC, et al. Molecular characterisation of acquired and overproduced chromosomal blaAmpC in Escherichia coli clinical isolates. Int J Antimicrob Agents. 2016;47:62-8.

62. Drinkovic D, Morris AJ, Dyet K, Bakker S, Heffernan H. Plasmid-mediated AmpC beta-lactamase-producing Escherichia coli causing urinary tract infection in the Auckland community likely to be resistant to commonly prescribed antimicrobials. N Z Med J. 2015;128:50-9.

63. Weissman SJ, Adler A, Qin X, Zerr DM. Emergence of extended-spectrum B-lactam resistance among Escherichia coli at a US academic children's hospital is clonal at the sequence type level for CTX-M-15, but not for CMY-2. Int J Antimicrob Agents. 2013;41:414-20.

64. Lorme F, Maataoui N, Rondinaud E, Esposito-Farèse M, Clermont O, Ruppe $\mathrm{E}$, et al. Acquisition of plasmid-mediated cephalosporinase producing Enterobacteriaceae after a travel to the tropics. PLOS ONE. 2018;13:e0206909.

65. Manga I, Hasman H, Smidkova J, Medvecky M, Dolejska M, Cizek A. Fecal carriage and whole-genome sequencing-assisted characterization of CMY-2 beta-lactamase-producing Escherichia coli in calves at Czech dairy cow farm. Foodborne Pathog Dis. 2019;16:42-53.

66. Findlay J, Gould V, North P, Bowker K, Williams MO, MacGowan AP, et al. Characterization of cefotaxime-resistant urinary Escherichia coli from primary care in South-West England 2017-18. J Antimicrob Chemother. 2020;75:65-71.

67. Sellera FP, Fernandes MR, Moura Q, Lopes RB, Souza TA, Cerdeira L, et al. Draft genome sequence of a blaCMY-2/Incl1-harbouring Escherichia coli D:ST457 isolated from coastal benthic organisms. J Glob Antimicrob Resist. 2018;14:83-4.
68. Cunha MP, Lincopan N, Cerdeira L, Esposito F, Dropa M, Franco LS, et al. Coexistence of CTX-M-2, CTX-M-55, CMY-2, FosA3, and QnrB19 in extraintestinal pathogenic Escherichia coli from poultry in Brazil. Antimicrob Agents Chemother. 2017;61:e02474-e2516.

69. Pannaraj PS, Bard JD, Cerini C, Weissman SJ. Pediatric carbapenemresistant Enterobacteriaceae in Los Angeles, California, a high-prevalence region in the United States. Pediatr Infect Dis J. 2015;34:11-6.

70. Hansen KH, Bortolaia V, Nielsen CA, Nielsen JB, Schønning K, Agersø Y, et al. Host-specific patterns of genetic diversity among Incl1-ly and IncK plasmids encoding CMY-2 $\beta$-lactamase in Escherichia coli isolates from humans, poultry meat, poultry, and dogs in Denmark. Appl Environ Microbiol. 2016;82:4705-14.

71. Accogli M, Fortini D, Giufrè M, Graziani C, Dolejska M, Carattoli A, et al. Incl1 plasmids associated with the spread of CMY-2, CTX-M-1 and SHV-12 in Escherichia coli of animal and human origin. Clin Microbiol Infect. 2013;19:E238-40.

72. Koga VL, Maluta RP, da Silveira WD, Ribeiro RA, Hungria M, Vespero EC, et al. Characterization of CMY-2-type beta-lactamase-producing Escherichia coli isolated from chicken carcasses and human infection in a city of South Brazil. BMC Microbiol. 2019;19:174.

73. Pepin-Puget L, El Garch F, Bertrand X, Valot B, Hocquet D. Genome analysis of enterobacteriaceae with non-wild type susceptibility to thirdgeneration cephalosporins recovered from diseased dogs and cats in Europe. Vet Microbiol. 2020;242:108601.

74. Vlieghe ER, Huang TD, Phe T, Bogaerts P, Berhin C, De Smet B, et al. Prevalence and distribution of beta-lactamase coding genes in third-generation cephalosporin-resistant Enterobacteriaceae from bloodstream infections in Cambodia. Eur J Clin Microbiol Infect Dis. 2015;34:1223-9.

75. Dziri O, Dziri R, Maraoub A, Chouchani C. Characterization of O25b-ST131 Escherichia coli clone producing CTX-M-15, DHA-4, and CMY-42 in urinary tract infections in a Tunisian island. Microb Drug Resist. 2020;26:741-6.

76. Pascual V, Ortiz G, Simó M, Alonso N, Garcia MC, Xercavins M, et al. Epidemiology and risk factors for infections due to AmpC $\beta$-lactamaseproducing Escherichia coli. J Antimicrob Chemother. 2015;70:899-904.

77. Park YS, Yoo S, Seo MR, Kim JY, Cho YK, Pai H. Risk factors and clinical features of infections caused by plasmid-mediated AmpC beta-lactamaseproducing Enterobacteriaceae. Int J Antimicrob Agents. 2009;34:38-43.

\section{Publisher's Note}

Springer Nature remains neutral with regard to jurisdictional claims in published maps and institutional affiliations.
Ready to submit your research? Choose BMC and benefit from:

- fast, convenient online submission

- thorough peer review by experienced researchers in your field

- rapid publication on acceptance

- support for research data, including large and complex data types

- gold Open Access which fosters wider collaboration and increased citations

- maximum visibility for your research: over $100 \mathrm{M}$ website views per year

At BMC, research is always in progress.

Learn more biomedcentral.com/submissions 